\title{
Vida Saludable: Letras en Desorden ${ }^{1}$
}

Linda B. Bobroff $^{2}$

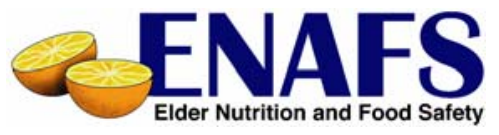

Ordene las letras en las siguientes palabras para escribir los nombres de algunos alimentos saludables. Después coloque cada una de las letras numeradas en los espacios indicados abajo para descifrar el mensaje.

\section{PRODUCTOS LÁCTEOS}

H L E E C 5

O E Q S U $--\overline{11}$

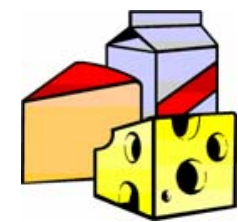

\section{CARNES Y FRIJOLES}

S A C O D E P $----\frac{-}{8}$

O S H V E U 14

E N S E U C<smiles>C=CC</smiles>

\section{VERDURAS}

L A C Z A A B A $---\frac{1}{12}----$

N C I E A S P A $\overline{10}$
FRUTAS

S U A V $1--$

A R F S E S $\frac{1}{3}---$

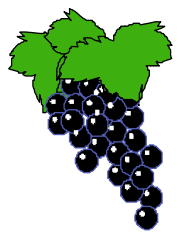

M A D A N R N A I

\section{GRANOS}

L A T R O I T L

OS D I E $-\frac{-}{6}---$

E V N A A

O S F D I E

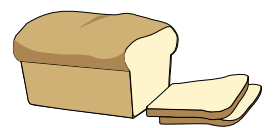

MENSAJE:

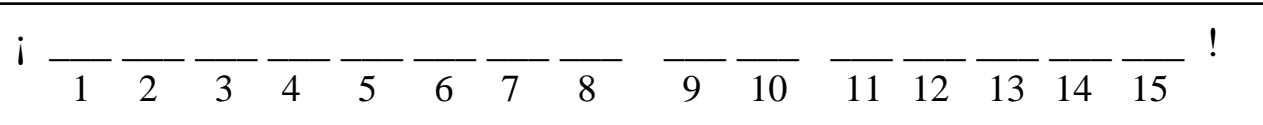

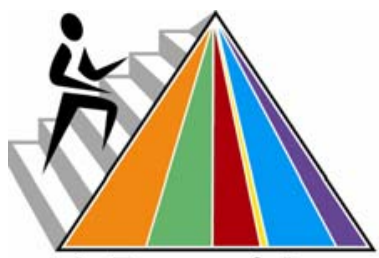

MyPyramid.gov STEPS TO A HEALTHIER YOU

1. The English version of this Spanish leaflet is Healthy Living: Scrambling for a Variety of Foods (FCS8615). Este folleto, FCS8615-Span, pertenece a una serie del Departamento de Ciencias de la Familia, Juventud y Comunidad, Servicio de Extensión Cooperativo de la Florida, Instituto de Alimentos y Ciencias Agrícolas, Universidad de la Florida. Fecha de publicación: marzo 2004. Revisado: octubre 2006. Favor de visitar el EDIS Web site en el http://edis.ifas.ufl.edu

2. Linda B. Bobroff, PhD, RD, LD/N, profesora, Departamento de Ciencias de la Familia, Juventud y Comunidad, Servicio de Extensión Cooperativo de la Florida, Instituto de Alimentos y Ciencias Agrícolas, Universidad de la Florida. Diseño y traducción por Paulina Wittkowsky, MS, RD, anteriormente con la Universidad de la Florida, Gainesville, FL 32611.

El Instituto de Alimentos y Ciencias Agrícolas es un empleador que provee Oportunidades Igualitarias, autorizado a proveer investigación, información educativa y otros servicios, únicamente a los individuos e instituciones que operan sin discriminación alguna con relación al credo, color, religión, edad, incapacidad, sexo, orientación sexual, estado civil, nacionalidad, opinión política o afiliaciones. Para más información sobre como obtener otras publicaciones de extensión, comuníquese con la oficina de Servicio de Extensión de su condado. Servicio de Extensión de la Florida / Instituto de Alimentos y Ciencias Agrícolas / Universidad de la Florida / Larry Arrington, Decano. 